\title{
Mechanochemical Synthesis and Characterization of Molybdenum Dioxide-Hematite Nanostructures with Different Molarities
}

\author{
Matthew Knauss'1, Felicia Tolea ${ }^{2}$, Mihaela Valeanu'2, Lucian Diamandescu2 ${ }^{2}$, Richard Trotta1, \\ Kelly Wood', Agnieszka Grabias ${ }^{3}$, Monica Sorescu' ${ }^{1}$
}

\author{
${ }^{1}$ Department of Physics, Duquesne University, Pittsburgh, USA \\ ${ }^{2}$ Department of Materials Science, National Institute of Materials Physics, Bucharest-Magurele, Romania \\ ${ }^{3}$ Department of Materials Science, Institute of Electronic Materials Technology, Warsaw, Poland \\ Email: sorescu@duq.edu
}

How to cite this paper: Knauss, M., Tolea, F., Valeanu, M., Diamandescu, L., Trotta, R., Wood, K., Grabias, A. and Sorescu, M. (2018) Mechanochemical Synthesis and Characterization of Molybdenum DioxideHematite Nanostructures with Different Molarities. Journal of Minerals and Materials Characterization and Engineering, 6, 587-600.

https://doi.org/10.4236/jmmce.2018.66042

Received: October 12, 2018

Accepted: November 18, 2018

Published: November 21, 2018

Copyright (c) 2018 by authors and Scientific Research Publishing Inc. This work is licensed under the Creative Commons Attribution International License (CC BY 4.0).

http://creativecommons.org/licenses/by/4.0/

\begin{abstract}
$\mathrm{xMoO}_{2}-(1-\mathrm{x}) \alpha-\mathrm{Fe}_{2} \mathrm{O}_{3}$ nanoparticle system with molarities $\mathrm{x}=0.1,0.3,0.5$ and 0.7 was successfully synthesized by mechanochemical activation of $\mathrm{MoO}_{2}$ and $\alpha$ - $\mathrm{Fe}_{2} \mathrm{O}_{3}$ mixtures for 0 - 12 hours of ball milling time. X-ray powder diffraction (XRD), Mössbauer spectroscopy and magnetic measurements were used to study the phase evolution of the molybdenum dioxide-hematite nanoparticle system under the mechanochemical activation process. Rietveld refinement of the XRD patterns yielded the values of the crystallite size and lattice parameters as function of milling times and indicated the presence of Mo-substituted hematite and Fe-doped molybdenum dioxide at long milling times. The Mössbauer studies yielded the magnetic hyperfine fields and the relative abundance of a quadrupole-split doublet as function of the milling time for all molar concentrations involved. Recoilless fraction was determined using our dual absorber method and was found to decrease with increasing ball milling time. Magnetic measurements recorded at 5 and $300 \mathrm{~K}$ in an applied magnetic field of 50,000 Oe showed the magnetic properties in the antiferromagnetic and canted ferromagnetic states. The Morin transformation was evidenced by zero-field cooling-field cooling (ZFC-FC) measurements in a magnetic field of 200 Oe.
\end{abstract}

\section{Keywords}

Milling, Spectroscopy, Magnetic Properties 


\section{Introduction}

Due to its potential applications in energy-related materials, catalysis and electrochemistry, molybdenum dioxide $\left(\mathrm{MoO}_{2}\right)$ is currently the subject of intense investigations. Thus, it has been proposed that surfactant-free self-assembly of reduced graphite oxide- $\mathrm{MoO}_{2}$ nanobelt composites can be used as electrode for lithium-ion batteries [1]. In a different study, $\mathrm{MoO}_{2}$ nanoparticles were found to serve as high capacity intercalation anode for long-cycle lithium ion battery [2]. In [3], the $\mathrm{MoO}_{2} / \mathrm{MoS}_{2}$ electrode indicates higher specific capacitance than that of pure $\mathrm{MoO}_{2}$ and pure $\mathrm{MoS}_{2}$. A facile hydrothermal method was proposed in [4] for the synthesis of $\mathrm{MoO}_{2}$ nanoparticles for high-performance supercapacitor electrodes and photocatalysts. In addition, the synthesis and electrochemical properties of $\mathrm{MoO}_{2} /$ reduced graphene oxide hybrid for efficient anode of lithium ion battery were reported [5]. A $\mathrm{MoO}_{2}$-based cathode for $\mathrm{CO}_{2}$ and $\mathrm{H}_{2} \mathrm{O}$ electrolysis was obtained in [6]. Hierarchical $\mathrm{MoO}_{2} / \mathrm{N}$-doped carbon heteronanowires with high rate and improved long-term performance for lithium ion batteries were subsequently developed [7]. Titanium-doped molybdenum dioxide system was obtained to study the kinetics of hydrogen reduction [8]. All these investigations point towards obtaining mixed systems of $\mathrm{MoO}_{2}$ nanoparticles and another system, which would be able to tailor its functional properties.

We chose this additional system to be hematite, as hematite has various applications in scientific and industrial fields and can be used as semiconductor compound [9], magnetic material [10], catalyst [11] and gas sensor [12]. In particular, nanocrystalline hematite obtained by high-energy ball milling was found to exhibit decreased grain size, expansion of lattice parameters and two kinds of particles which coexist in the sample: Nanostructured and micrometer hematite [13].

Conventional and magnetic ball milling techniques have emerged lately as green methods used to synthesize novel phases at moderate temperatures in an environmentally friendly fashion. Recently, the authors have undertaken several investigations on mechanochemical synthesis of various nanostructured oxide systems [14]. In this paper, the authors report the successful synthesis of molybdenum dioxide-hematite nanoparticles systems with different molarities $(x=0.1$, $0.3,0.5$ and 0.7 ). The synthesis was carried out using the mechanochemical activation method. The ball-milling of molybdenum dioxide and hematite mixtures was performed at room temperature at milling times in the range $0-12$ hours. The structural, magnetic and hyperfine properties of the molybdenum dioxide-hematite nanocomposites were investigated using X-ray powder diffraction, Mössbauer spectroscopy and magnetic measurements as function of processing parameters.

\section{Materials and Methods}

Nanocomposites of $\mathrm{xMoO}_{2}-(1-\mathrm{x}) \alpha-\mathrm{Fe}_{2} \mathrm{O}_{3}$ have been obtained using high energy ball milling starting from precursor powder of molybdenum and iron oxides purchased from Alfa Aesar. The starting average particle sizes were 100 and 50 
nm for $\mathrm{MoO}_{2}$ and $\mathrm{Fe}_{2} \mathrm{O}_{3}$, respectively and their purity was better than $99.9 \%$. Samples of hematite and molybdenum oxides were introduced in a stainless-steel cylinder with 12 stainless-steel balls using the SPEX 8000 mixer mill for milling periods of time selected in the range 0 to $12 \mathrm{~h}$. The powder: ball mass ratio used throughout the experiments was 1:5. A homogeneous mixture of the starting powders was obtained by manually grinding the samples in air prior to introduction in the milling chamber. A PANalytic X'Pert Pro MPO powder diffractometer with $\mathrm{CuK}_{\alpha}$ radiation $(45 \mathrm{kV} / 40 \mathrm{~mA}, \lambda=1.54187 \AA$ ) was used to obtain the powder diffraction patterns of the molybdenum oxide hematite particles at all molarities studied. The X'cellerator detector was employed and a scan range of $2 \theta$ from 10 to $80^{\circ}$ with a preselected step size of $0.02^{\circ}$. The Scherrer method was employed in order to derive the average sizes of the crystallites for all different molarities. The Rietveld structural refinement of the XRD patterns was utilized to derive the optimized values of the lattice parameters for both molybdenum dioxide and hematite phases. ${ }^{57} \mathrm{Fe}$ Mössbauer spectra were recorded at room temperature in the transmission geometry using a state-of-the-art SeeCo constant acceleration spectrometer. A $25 \mathrm{mCi}{ }^{57} \mathrm{Co}$ source diffused in a $\mathrm{Rh}$ matrix was used in all experiments. Least-squares fittings of the Mössbauer spectra were performed in the assumption of Lorentzian lineshapes using the WinNormos package of programs. Hysteresis magnetic measurements were performed in the temperature range $5-300 \mathrm{~K}$ in an applied magnetic field up to 50,000 Oe while zero-field cooling was done at 200 Oe. All measurements were performed using a Quantum Design SQUID magnetometer.

\section{Results and Discussions}

Figures 1-4(a)-(e) represent the XRD patterns of molybdenum dioxide-hematite system at different molarities, corresponding to milling times between 0 and 12 h. For the ball-milled composites (Figures 1-4(b)-(e)), the XRD patterns show slight peak broadening with milling time. This peak broadening is associated with the decrease in crystallite sizes for both hematite and molybdenum dioxide samples. It can also be seen that the diffraction peak intensities of hematite and molybdenum phases decrease with the increase in ball-milling time, indicating the possible ion substitutions between $\mathrm{Mo}^{4+}$ and $\mathrm{Fe}^{3+}$ in the corresponding hematite and molybdenum dioxide lattices.

Figure 5(a) shows the lattice parameter a for hematite as function of ball milling time for all molarities and milling times employed, while Figure 5(b) displays the parameter $c$ for hematite determined using the Rietveld refinement method. It can be seen that the lattice parameter $a$ increases with milling time for all values of the molarities employed, with the exception of the equimolar concentration $(\mathrm{x}=0.5)$ which exhibits steady values. As well, it can be noticed that the lattice parameter $c$ increases slightly with ball milling time while it exhibits a more pronounced increase for molar concentration $\mathrm{x}=0.7$. This is due to Mo substituting $\mathrm{Fe}$ in the hematite lattice and this substitution is in principle possible, based on the values of the ionic radii for the two ions ( 65 pm). 


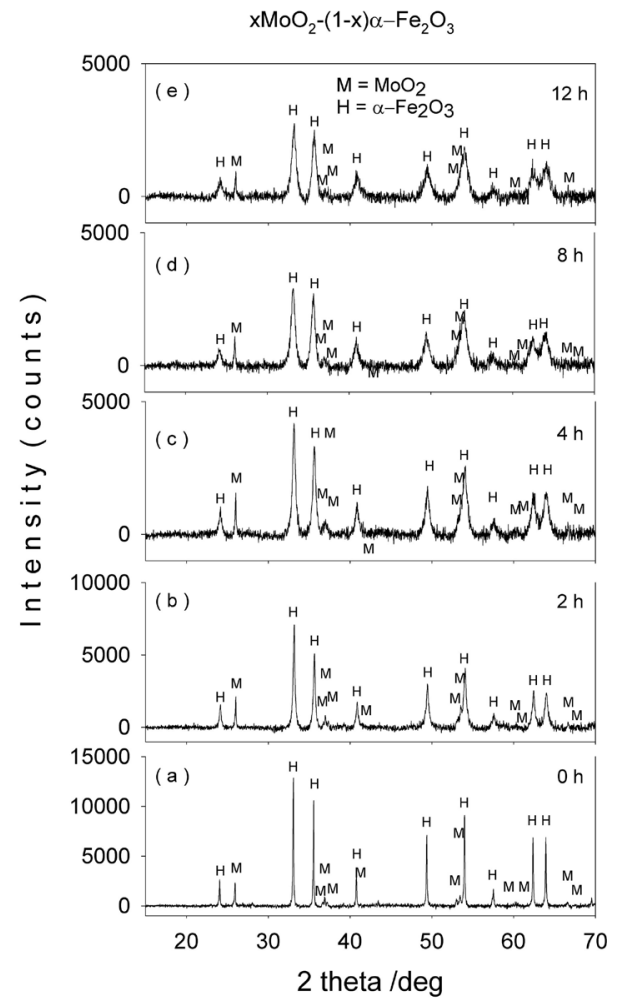

Figure 1. XRD patterns of mechanochemically activated $\mathrm{MoO}_{2}-\mathrm{Fe}_{2} \mathrm{O}_{3}$ composites $(\mathrm{x}=0.1)$ at ball milling time of (a) 0 hour; (b) 2 hours; (c) 4 hours; (d) 8 hours; (e) 12 hours.

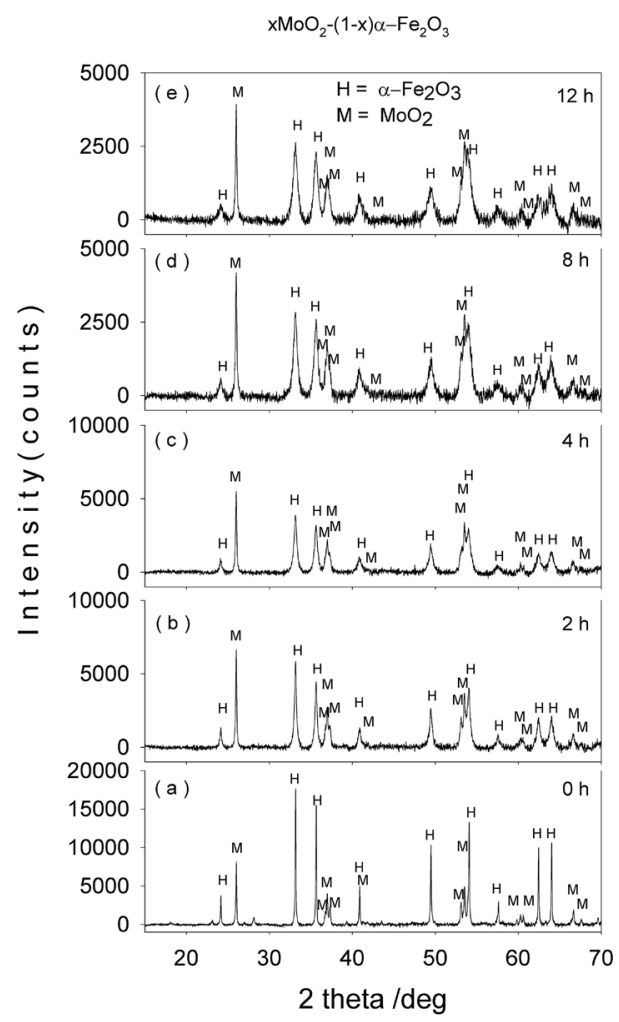

Figure 2. XRD patterns of mechanochemically activated $\mathrm{MoO}_{2}-\mathrm{Fe}_{2} \mathrm{O}_{3}$ composites $(\mathrm{x}=0.3)$ at ball milling time of (a) 0 hour; (b) 2 hours; (c) 4 hours; (d) 8 hours; (e) 12 hours. 


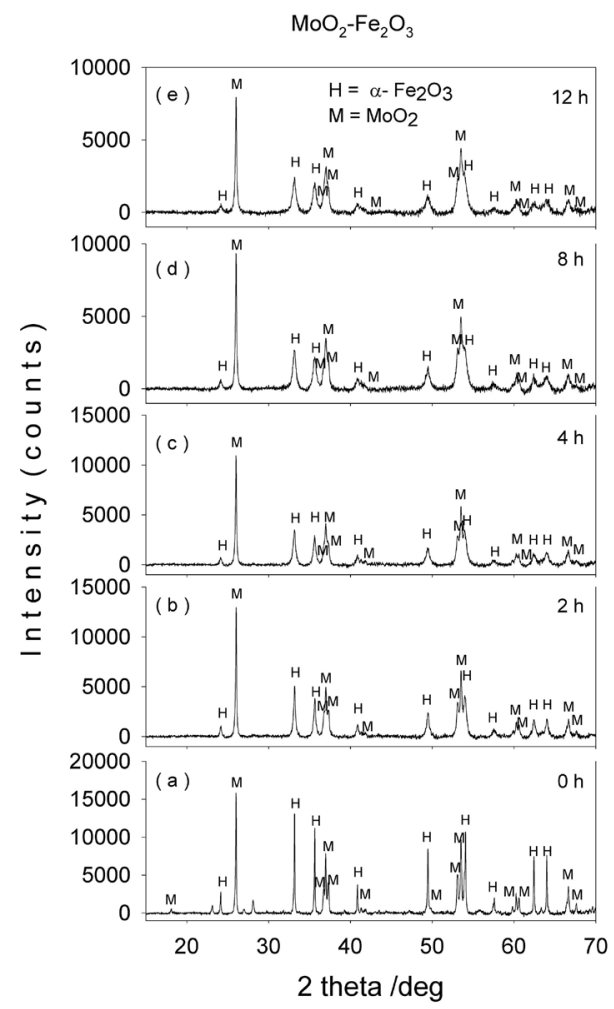

Figure 3. XRD patterns of mechanochemically activated $\mathrm{MoO}_{2}-\mathrm{Fe}_{2} \mathrm{O}_{3}$ composites $(\mathrm{x}=0.5)$ at ball milling time of (a) 0 hour; (b) 2 hours; (c) 4 hours; (d) 8 hours; (e) 12 hours.

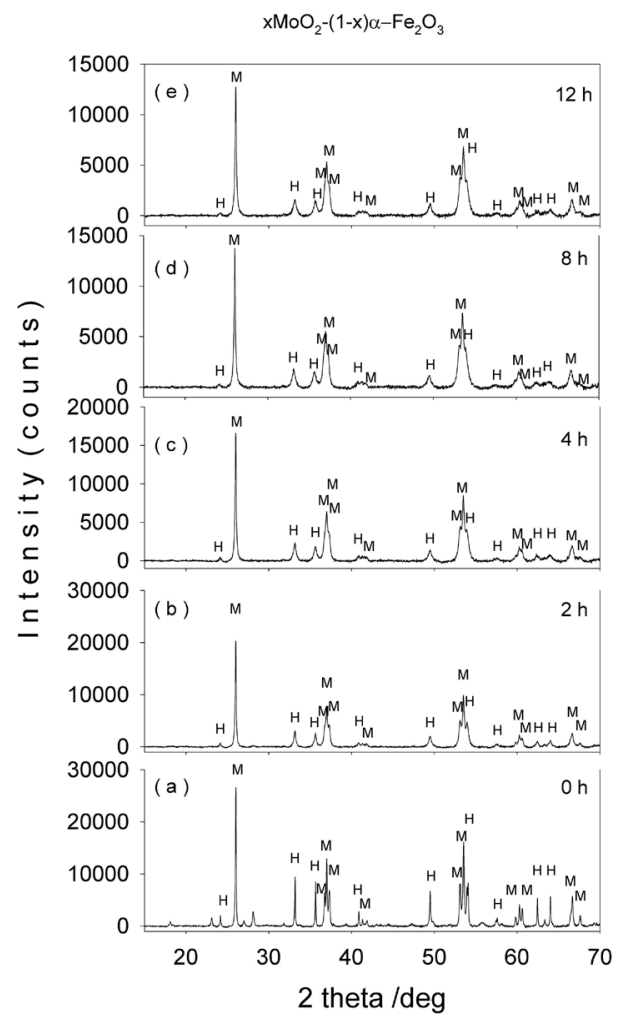

Figure 4. XRD patterns of mechanochemically activated $\mathrm{MoO}_{2}-\mathrm{Fe}_{2} \mathrm{O}_{3}$ composites $(\mathrm{x}=0.7)$ at ball milling time of (a) 0 hour; (b) 2 hours; (c) 4 hours; (d) 8 hours; (e) 12 hours. 

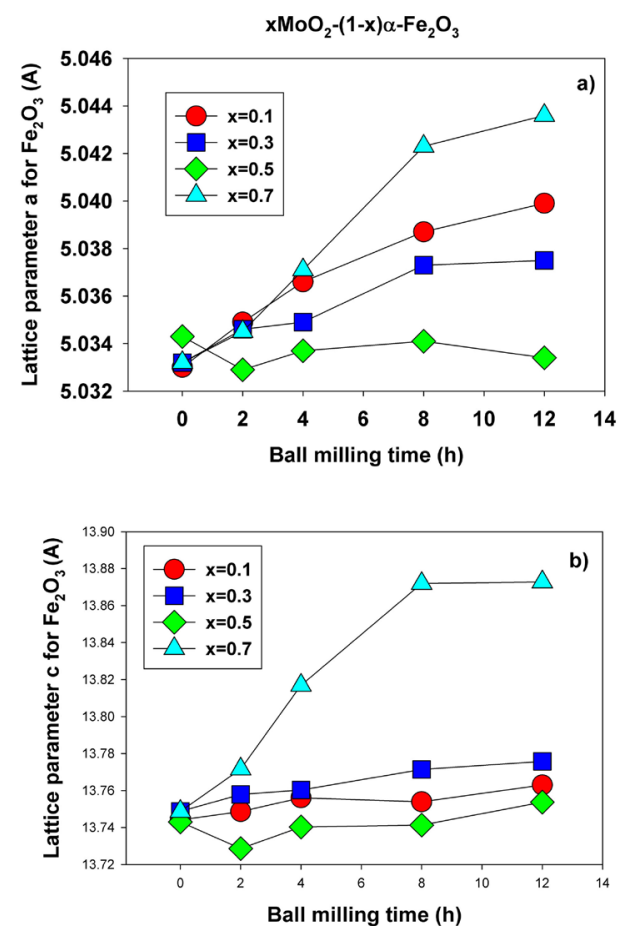

Figure 5. Lattice parameters $a(a)$ and $c$ (b) for hematite at different molarities and ball milling times.

Figure 6(a) shows the lattice parameter a for molybdenum dioxide as function of ball milling time for all molarities and milling times employed, while Figure 6(b) displays the parameter $c$ for molybdenum dioxide for the same values of the processing parameters. Overall, both lattice parameters show a steady evolution with the milling time for all values of the molar concentrations employed.

The values of the crystallite size for both hematite and molybdenum dioxide phases were determined from the XRD patterns using the Scherrer method and plotted in Figure 7(a) and Figure 7(b), respectively.

It can be seen that the crystallite size decreases as function of milling time for all molar concentrations employed. For $\mathrm{x}=0.5$, for instance, molybdenum-doped hematite and molybdenum dioxide are the only crystalline phases present after 2 hours of milling time, with an average crystallite size decreased to 38.9 and 72.5 $\mathrm{nm}$, respectively. This crystalline size decreases even further, down to 17.7 and $49.9 \mathrm{~nm}$ after 12 hours of mechanochemical activation. During the milling process, a microstrain concentrates in the lattice and increases the lattice distortion and strain energy. The increase in the lattice distortion, decrease in grain size, and ions substitution result in the variation of lattice parameters $a$ and $c$. In fact, it is well documented in the literature that lattice parameter changes, either contraction or expansion, are expected when the grain sizes decrease as compared to the values of bulk materials.

Figures 8-11(a)-(e) show the room temperature transmission Mössbauer spectra of the molybdenum dioxide-hematite composites with various molari- 
ties, after ball milling for $0,2,4,8$ and 12 hours, respectively. The hyperfine parameters corresponding to these spectra are given in Figure 12.
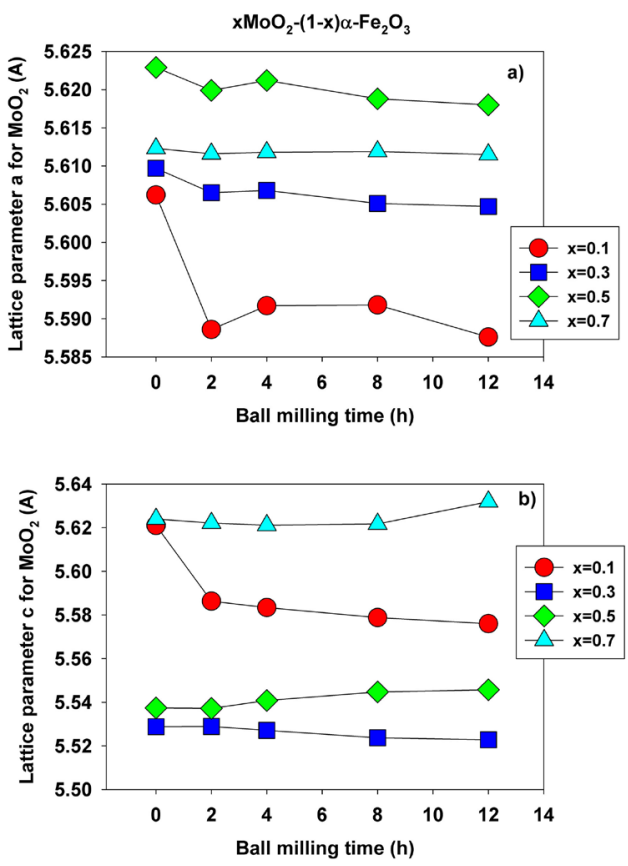

Figure 6. Lattice parameters $a(a)$ and $c$ (b) for molybdenum dioxide at different molarities and ball milling times.
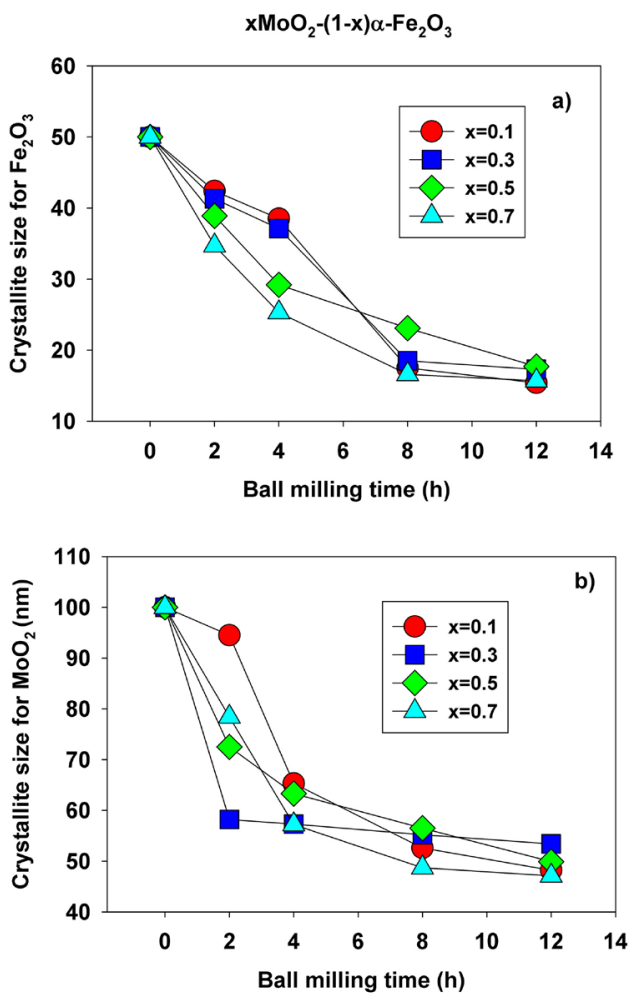

Figure 7. Crystallite sizes for hematite (a) and molybdenum dioxide (b) at different molarities and ball milling times. 


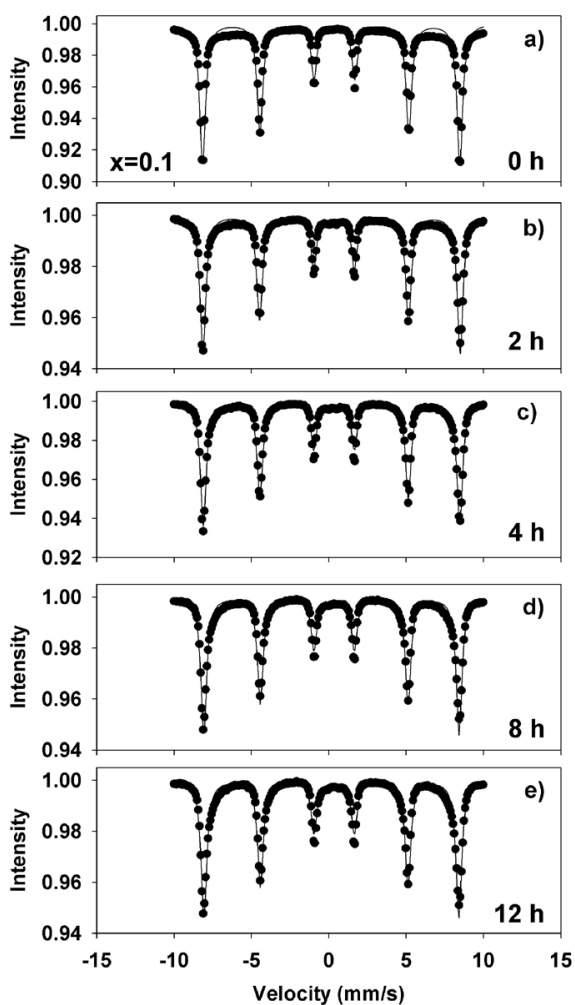

Figure 8. Mössbauer spectra of mechanochemically activated $\mathrm{MoO}_{2}-\mathrm{Fe}_{2} \mathrm{O}_{3}$ composites $(\mathrm{x}=$ 0.1 ) at ball milling time of: (a) 0 hour; (b) 2 hours; (c) 4 hours; (d) 8 hours; (e) 12 hours.
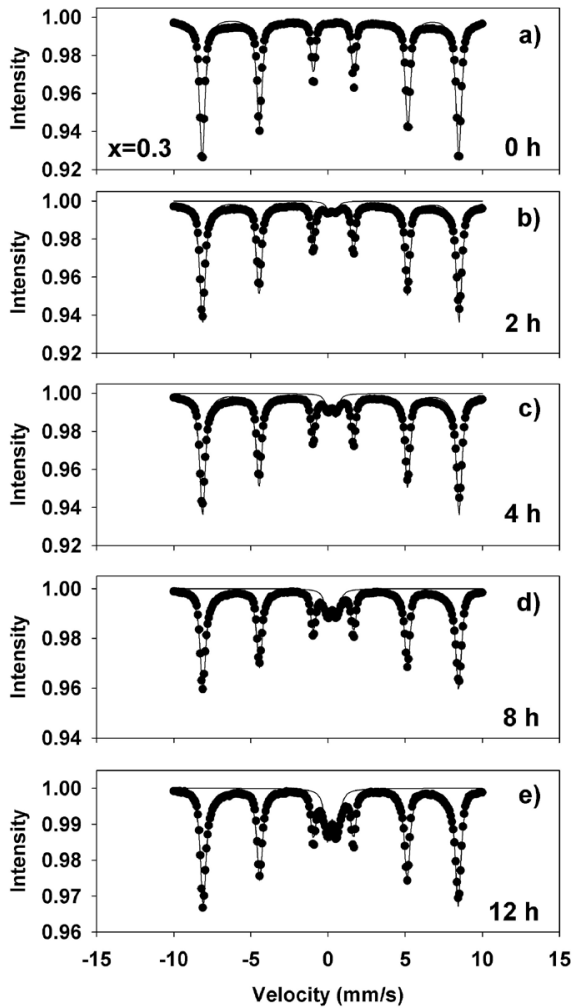

Figure 9. Mössbauer spectra of mechanochemically activated $\mathrm{MoO}_{2}-\mathrm{Fe}_{2} \mathrm{O}_{3}$ composites $(\mathrm{x}=$ 0.3 ) at ball milling time of: (a) 0 hour; (b) 2 hours; (c) 4 hours; (d) 8 hours; (e) 12 hours. 


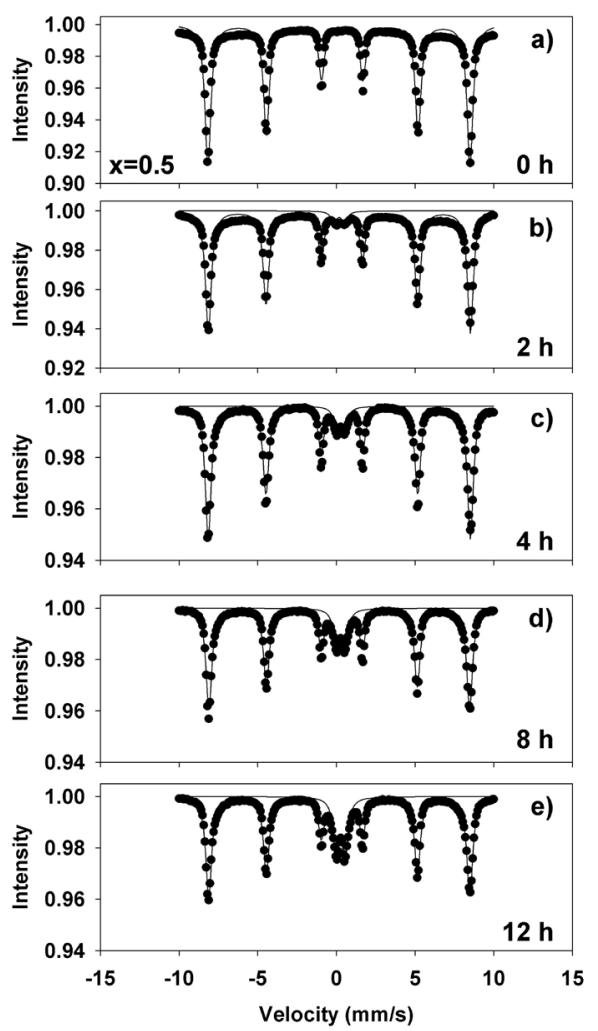

Figure 10. Mössbauer spectra of mechanochemically activated $\mathrm{MoO}_{2}-\mathrm{Fe}_{2} \mathrm{O}_{3}$ composites ( $\mathrm{x}$ $=0.5$ ) at ball milling time of: (a) 0 hour; (b) 2 hours; (c) 4 hours; (d) 8 hours; (e) 12 hours.
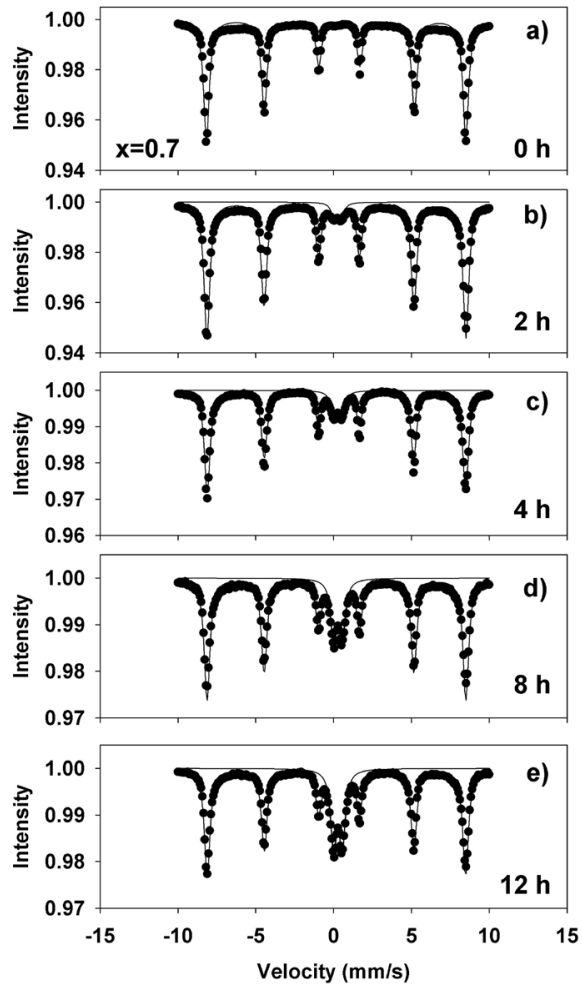

Figure 11. Mössbauer spectra of mechanochemically activated $\mathrm{MoO}_{2}-\mathrm{Fe}_{2} \mathrm{O}_{3}$ composites (x $=0.7$ ) at ball milling time of: (a) 0 hour; (b) 2 hours; (c) 4 hours; (d) 8 hours; (e) 12 hours. 

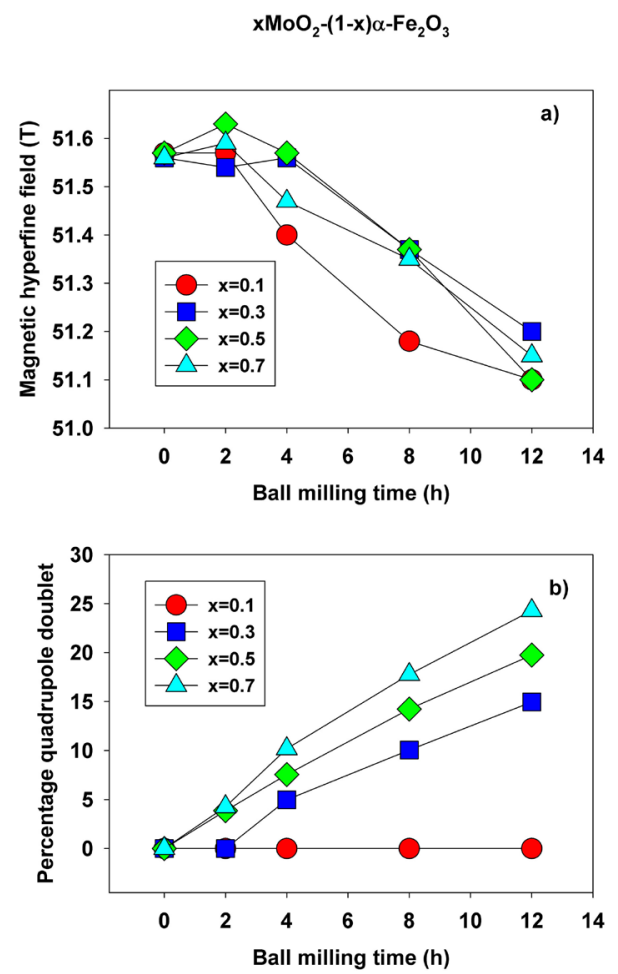

Figure 12. Magnetic hyperfine field (a) and percentage of quadrupole doublet (b) as function of molarity and ball milling time.

At $0 \mathrm{~h}$ of milling time, the spectra were fitted with 1 sextet with a magnetic hyperfine field of $51.65 \mathrm{~T}$ (Figures 8-11(a)), corresponding to $\alpha-\mathrm{Fe}_{2} \mathrm{O}_{3}$. The spectra corresponding to 2 - 12 hours were fitted with one sextet with decreasing values of the hyperfine field (Figure 12(a)) and a quadrupole split doublet. These sextets correspond to Fe ions having a different number of Mo as nearest neighbors and demonstrate the onset of Mo substitutions for Fe in the hematite lattice. For $\mathrm{x}=0.5$, for instance, the hyperfine magnetic field decreases from $51.65 \mathrm{~T}$ to $51.37 \mathrm{~T}$. However, we did not observe multiple sextets for each spectrum, such that there is only a limited solubility of Mo in the hematite lattice. This is reinforced by the values taken by the linewidth, which increases from 0.3 to $0.45 \mathrm{~mm} / \mathrm{s}$ in Figures 8-11(b)-(e), supporting the existence of Mo-substituted hematite, in qualitative agreement with the XRD results.

The quadrupole doublet corresponds to Fe substituting $\mathrm{Mo}$ in the $\mathrm{MoO}_{2}$ lattice, giving rise to a nonmagnetic phase (Figure 12(b)). Its abundance increases steadily with the milling time for all values of the molar concentration considered in the study. We propose that the relative area of this doublet is a measure of the Fe substitutions for Mo. Figure 13(a) shows an example of the transmission Mössbauer spectrum of the $\mathrm{xMoO}_{2}-(1-\mathrm{x}) \alpha-\mathrm{Fe}_{2} \mathrm{O}_{3}$ sample $(\mathrm{x}=0.5)$ after 8 hours of ball milling, recorded simultaneously with a stainless steel etalon in order to determine the recoilless fraction based on our previously proposed dual absorber method [15]. The spectrum was fitted using an additional singlet with negative isomer shift of $-0.27 \mathrm{~mm} / \mathrm{s}$, representing the stainless-steel etalon. 
From the relative areas and chemical arguments, we could derive the values of the recoilless fraction $f_{1}$ :

$$
f_{1}=f_{e}\left(N_{e} / N_{1}\right)\left(\mu_{1} / \mu_{e}\right)\left(m_{e} / m_{1}\right)\left(A_{1} / A_{e}\right)
$$

where $f_{e}$ is the recoilless fraction of the stainless-steel etalon, $N_{e}$ and $N_{1}$ are the numbers of iron nuclei per formula unit for etalon and sample, $\mu_{1}$ and $\mu_{\mathrm{e}}$ are the molar masses for the sample and etalon, $m_{\mathrm{e}}$ and $m_{1}$ are the masses corresponding to the etalon and sample, and $A_{1}$ and $A_{e}$ are the resonant areas for the sample and etalon, respectively.

Figure 13(b) presents the values determined for the $f$ factor as function of ball milling time for $\mathrm{x}=0.5$. It can be seen that the recoilless fraction decreases from 0.4 at 0 hours to 0.18 at 12 hours of milling time. Indeed, longer milling times correlate with smaller crystallite sizes and consequently, lower values for the $f$ factor.

Figure 14(a) and Figure 14(b) show the hysteresis loops of equimolar molybdenum-doped hematite samples for different ball milling times recorded at 300 and $5 \mathrm{~K}$ respectively, in an applied magnetic field up to 50,000 Oe. At $5 \mathrm{~K}$, the dependence of magnetization on the applied field for the 0-hour sample is practically a straight line, as the sample is in the antiferromagnetic (AF) state. As the milling time is increased, the magnetic susceptibility is enhanced probably first, due to some surface effects induced by the grinding process and second, due to the new magnetic phases with Mo substitutions for Fe in the hematite lattice, which add increasingly higher contributions. The hysteresis loops measured at $300 \mathrm{~K}$ reveal the canted ferromagnetism (above the Morin transformation), the saturation not being reached even for $5 \mathrm{~T}$.

Figure 15 shows the zero-field-cooling-field-cooling experiment performed on the equimolar composition milled for $0-12$ hours in an applied field of 200 Oe between 5 and $300 \mathrm{~K}$. While heating pure hematite, the magnetization should be zero (antiferromagnet) below the Morin temperature [16] and above that temperature, the magnetization should suddenly increase because the spins are no longer antiparallel. If all hematite crystallites had the same dimension and the structure was perfect, this increase should be a step. Due to milling, the average crystallite size decreases and the Morin temperature (which depends on the crystallite size) takes lower values and are distributed over a temperature range. Consequently, the transformation is not a step any more, but resembles an incline.

\section{Conclusion}

Molybdenum dioxide-hematite nanoparticle system of the type $\mathrm{xMoO}_{2}-(1-\mathrm{x}) \alpha-\mathrm{Fe}_{2} \mathrm{O}_{3}$ with different molarities $(\mathrm{x}=0.1,0.3,0.5,0.7)$ was successfully synthesized using mechanochemical activation for times ranging from 0 to 12 hours. The structural and magnetic properties of the system were investigated using XRD, Mössbauer spectroscopy, hysteresis and zero-field cooling measurements. The 

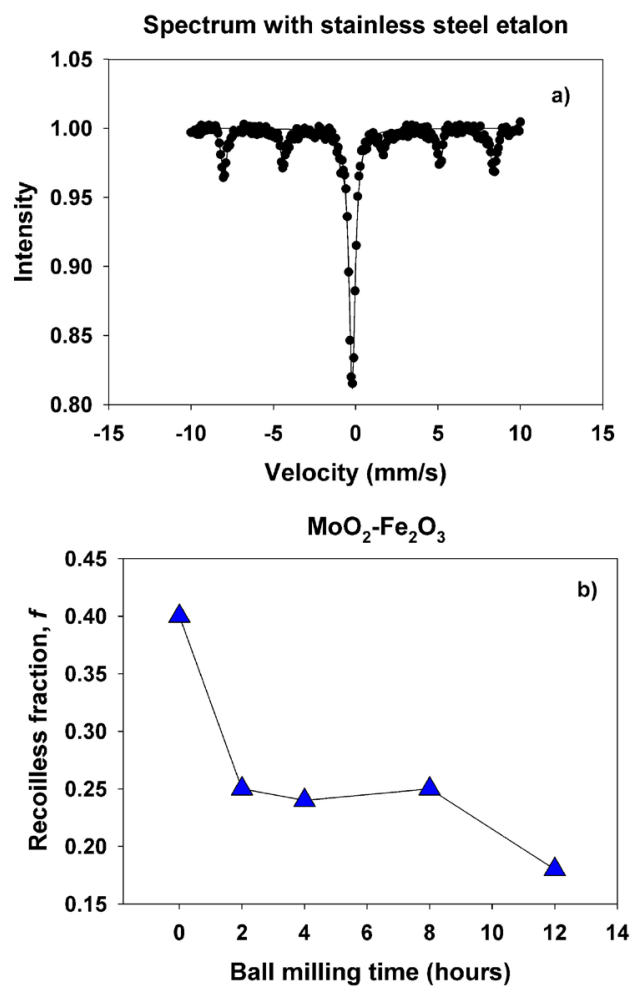

Figure 13. Spectrum with stainless steel etalon (a) and recoilless fraction (b) for $x=0.5$ and milling time of $0-12$ hours.
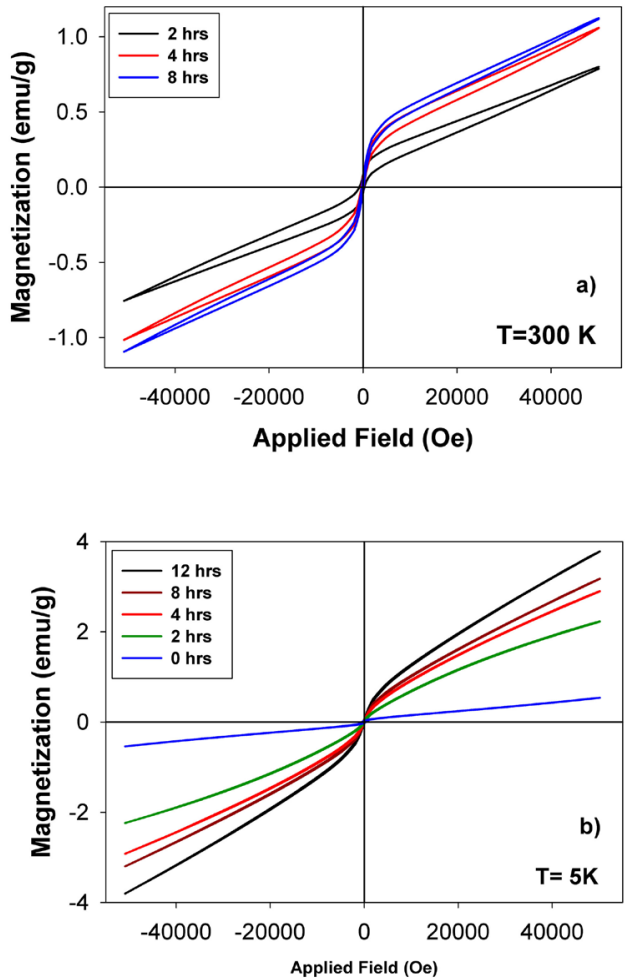

Figure 14. (a) Hysteresis loops of the molybdenum dioxide-hematite equimolar system recorded at $300 \mathrm{~K}$ in a magnetic field of $5 \mathrm{~T}$. (b) Hysteresis loops of the molybdenum dioxide-hematite equimolar system recorded at $5 \mathrm{~K}$ in a magnetic field of $5 \mathrm{~T}$. 


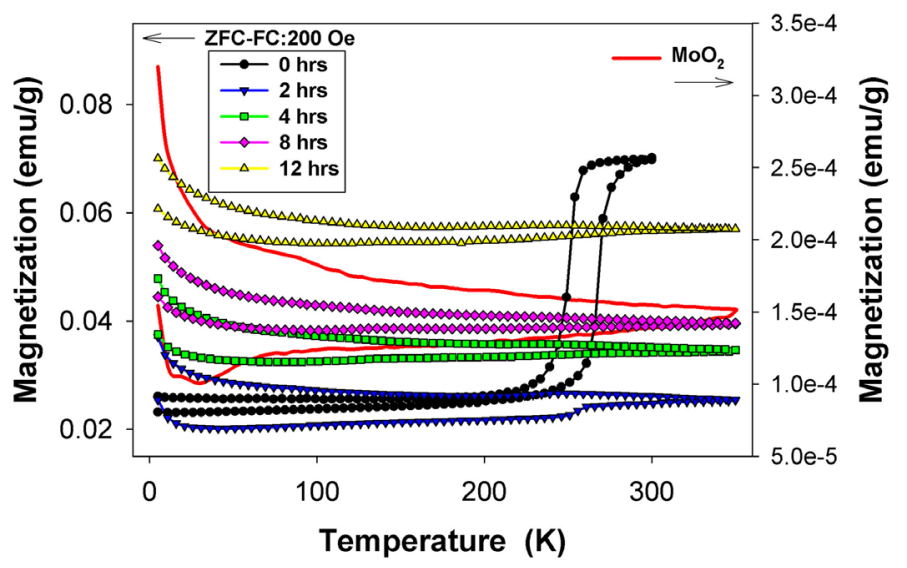

Figure 15. Zero-field-cooling-field cooling experiment performed in applied field of 200 Oe between 5 and $300 \mathrm{~K}$.

lattice parameters, average crystallite size, hyperfine parameters, phase evolution and magnetic properties were derived using these techniques. Compared to other mixed-oxide ceramic semiconductor systems investigated previously, the molybdenum system singles out due to the convincing demonstration of limited solubility during mutual substitutions between the two main phases present: Mo-containing hematite and Fe-containing molybdenum dioxide.

\section{Acknowledgements}

This work was supported by the National Science Foundation, USA under grants DMR-0854794 and DMR-1002627-1. The authors from the National Institute of Materials Physics-Romania, thank the support of the Core program PN 10N, as well as of the European Union and Romanian Government, under POS-CCE project CEUREMAVSU-Nr. 01/01.03.2009, allowing the acquisition of the research infrastructure.

\section{Conflicts of Interest}

The authors declare no conflicts of interest regarding the publication of this paper.

\section{References}

[1] Zhu, M.Y., Xu, X., Chen, G., Zhong, Y., Cai, R., Li, L. and Shao, Z. (2016) Surfactant-Free Self-Assembly of Reduced Graphite Oxide- $\mathrm{MoO}_{2}$ Nanobelt Composites Used as Electrodes for Lithium Ion Batteries. Electrochimica Acta, 211, 972-981. https://doi.org/10.1016/j.electacta.2016.06.139

[2] Zhang, X., Hou, Z., Li, X., Liang, J., Zhu, Y. and Qian, Y. (2016) $\mathrm{MoO}_{2}$ Nanoparticles as High Capacity Intercalation Anode Material for Long Cycle Lithium Ion Battery. Electrochimica Acta, 213, 416-422. https://doi.org/10.1016/j.electacta.2016.07.134

[3] Zhang, T., Kong, L.B., Liu, M.C., Dai, Y.H., Yan, K., Hu, B., Luo, Y.C. and Kang, L. (2016) Design and Preparation of $\mathrm{MoO}_{2} / \mathrm{MoS}_{2}$ as Negative Electrode Materials for Supercapacitors. Materials and Design, 112, 88-96. 
https://doi.org/10.1016/j.matdes.2016.09.054

[4] Zhou, E., Wang, C., Zhao, Q., Li, Z., Shao, M., Deng, X., Liu, X. and Xu, X. (2016) Facile Synthesis of $\mathrm{MoO}_{2}$ Nanoparticles as High-Performance Supercapacitor Electrodes and Photocatalysts. Ceramics International, 42, 2198-2203.

https://doi.org/10.1016/j.ceramint.2015.10.008

[5] Zhang, C., Zhang, P., Dai, J., Zhang, H., Xie, A. and Shen, Y. (2016) Facile Synthesis and Electrochemical Properties of $\mathrm{MoO}_{2}$ /Reduced Grapheme Oxide Hybrid for Efficient Anode of Lithium Ion Battery. Ceramics International, 42, 3618-3624. https://doi.org/10.1016/j.ceramint.2015.11.026

[6] Hou, X., Zhao, K., Yang, J.I. and Ha, S. (2016) $\mathrm{MoO}_{2}$-Based Cathode for $\mathrm{CO}_{2}$ and $\mathrm{H}_{2} \mathrm{O}$ Electrolysis. International Journal of Hydrogen Energy, 41, 11895-11899. https://doi.org/10.1016/j.ijhydene.2016.05.080

[7] Yang, L.C., Sun, W., Zhong, Z.W., Liu, J.W., Gao, Q.S., Hu, R.Z. and Zhu, M. (2016) Hierarchical $\mathrm{MoO}_{2} / \mathrm{N}$-Doped Carbon Heteronanowires with High Rate and Improved Long-Term Performance for Lithium Ion Batteries. Journal of Power Sources, 306, 78-84. https://doi.org/10.1016/j.jpowsour.2015.11.073

[8] He, Q., Flores, O.M., Hu, S., Scudiero, L., Ha, S. and Norton, M.G. (2015) Kinetics of Hydrogen Reduction of Titanium-Doped Molybdenum Dioxide. Scripta Materialia, 100, 55-58. https://doi.org/10.1016/j.scriptamat.2014.12.012

[9] Wang, G.X., Gou, X.L., Horvat, J. and Park, J. (2008) Facile Synthesis and Characterization of Iron Oxide Semiconductor Nanowires for Gas Sensing Application. Journal of Physical Chemistry C, 112, 15220-15225. https://doi.org/10.1021/jp803869e

[10] Raffaella, B., Etienne, S., Cinzia, G., Fabia, G., Mar, G.H., Miguel, A.G., Roberto, C. and Pantaleo, D.C. (2009) Colloidal Semiconductor/Magnetic Heterostructures Based on Iron-Oxide-Functionalized Brookite $\mathrm{TiO}_{2}$ Nanorods. Physical Chemistry Chemical Physics, 11, 3680-3691. https://doi.org/10.1039/b821964h

[11] Krishnamoorthy, S., Rivas, J.A. and Amiridis, M.D. (2000) Catalytic Oxidation of 1,2-Dichlorobenzene over Supported Transition Metal Oxides. Journal of Catalysis, 193, 264-272. https://doi.org/10.1006/jcat.2000.2895

[12] Sorescu, M., Diamandescu, L., Tomescu, A., Tarabasanu-Mihaila, D. and Teodorescu, V. (2008) Structure and Sensing Properties of $0.1 \mathrm{SnO}_{2}-0.9 \mathrm{Fe}_{2} \mathrm{O}_{3}$ System. Materials Chemistry and Physics, 107, 127-131. https://doi.org/10.1016/j.matchemphys.2007.06.062

[13] Lemine, O.M., Sajieddine, M., Bououdina, M., Msalam, R., Mufti, S. and Alyamani, A. (2010) Rietveld Analysis and Mössbauer Spectroscopy Studies of Nanocrystalline Hematite $\alpha-\mathrm{Fe}_{2} \mathrm{O}_{3}$. Journal of Alloys and Compounds, 502, 279-282. https://doi.org/10.1016/j.jallcom.2010.04.175

[14] Allwes, M., Mekaoui, M. and Sorescu, M. (2017) Mutual Solubility of Scandium Oxide-Hematite Magnetic Nanocomposites: Mössbauer Spectroscopy Investigation. Solid State Communnications, 261, 46-49. https://doi.org/10.1016/j.ssc.2017.05.023

[15] Sorescu, M. (2002) A New Method for Direct Determination of the Recoilless Fraction Using a Single Room-Temperature Mössbauer Measurement of a Two-Foil Absorber. Materials Letters, 54, 256-259. https://doi.org/10.1016/S0167-577X(01)00572-9

[16] Diaz-Guerra, C., Perez, L., Piqueras, J. and Chioncel, M.F. (2009) Magnetic Transitions in $\mathrm{Fe}_{2} \mathrm{O}_{3}$ Nanowires. Journal of Applied Physics, 106, 104302. https://doi.org/10.1063/1.3259394 